\title{
Airway Management in a Pediatric Patient with Xeroderma Pigmentosum: A Case Report
}

Seyedhejazi Mahin ${ }^{1}$, Dehdilani Marjan ${ }^{2 *}$, Gaffarlou Mehdi², Aliakbari Sharabiani Behzad ${ }^{2}$

1. Associate Professor of pediatric anesthesia, Department of Anesthesiology, Tabriz Children Hospital, Tabriz University of Medical Sciences, Tabriz, Iran

2. Anesthesiologist, Department of Anesthesiology, Tabriz Children Hospital, Tabriz University of Medical Sciences, Tabriz, Iran

\begin{abstract}
Xeroderma pigmentosum (XP) is a rare genetic disorder with a recessive autosomal inheritance. It seems that total intravenous anesthesia (TIVA) is more appropriate than inhalational anesthesia as a method for maintenance of general anesthesia for xeroderma pigmentosum patients and the airway manipulation must be performed as little and noninvasive as possible. The aim of this report was to evaluate the specific considerations for airway management and anaesthesia in these patients.
\end{abstract}

Keywords: Xeroderma pigmentosum; Airway management; Pediatric; Anesthesia; Total intravenous anesthesia

\section{Introduction}

Xeroderma pigmentosum (XP) is a rare genetic disorder with a recessive autosomal inheritance (1-5), which is characterized by hypersensitivity of the skin to ultraviolet (UV)radiation and results in premature development of neoplasias and progressive neurological complications $(2,3)$ The underlying mechanism is deletion and reconstruction of DNA. These patients are at excessively high risk of skin cancer on sun-exposed areas compared to normal individuals $(4,5)$. The aim of this report was to evaluate specific anesthetic and airway considerations in these patients.

\section{CASE REPORT}

We report a 9-year-old, $24 \mathrm{~kg}$ male with XP who underwent parotid abscess drainage and several malignant skin tumors excisional biopsies in our center. He had history of brown and extensive spot lesions since three years of

\section{Corresponding author:}

Marjan Dehdilani

Department of Anesthesiology, Tabriz Children Hospital, Tabriz University of Medical Sciences, Tabriz, Iran

Tel:+989141144811 Email: md56422@yahoo.com

Receive date: 2014-03-02 | Accept date: 2014-03-20 | Publish date: 2014-04-06

DOI: 10.7575/aiac.abcmed.15.03.01.12

\section{A. I}


age. His parotid mass increased in size within the previous fifteen days. CT scan and ultrasonography reported a cystic lesion; consequently, the patient was scheduled for abscess drainage. In preoperative visit, he was alert and oriented. His only complication was photophobia. There was not any history of neurologic signs or convulsion. In the airway evaluation, there was limitation of mouth opening and Mallampati of grade two without any obvious mucosal lesions.

Patient was premedicated with $0.5 \mathrm{mg}$ IV midazolam and 20mcg IV Fentanyl. Initial monitoring consisted of ECG, pulse oximetry,

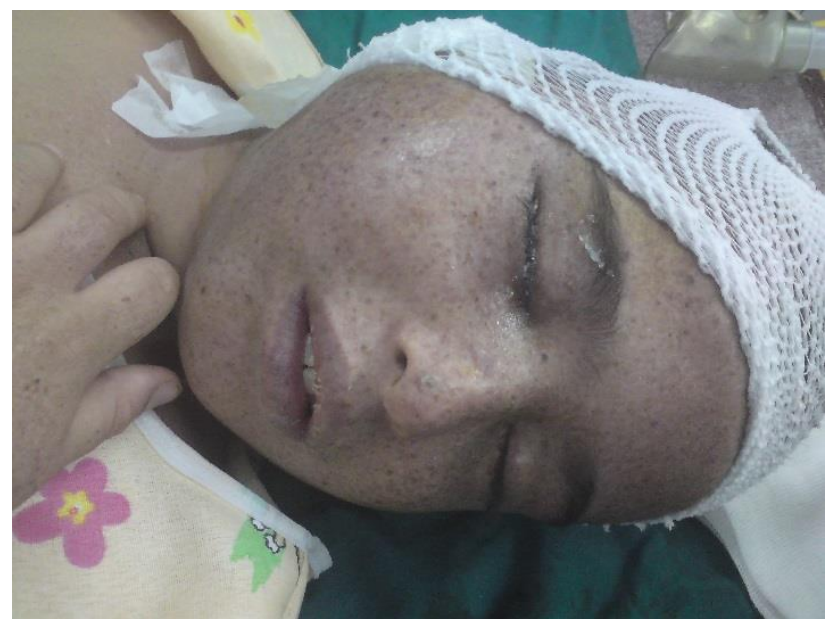

precordial stethoscope and noninvasive blood pressure. Patient was pre oxygenated with $100 \%$ oxygen for 3 minutes. Induction was performed with $25 \mathrm{mg}$ lidocaine, $60 \mathrm{mg}$ propofol. LMA size 2.5 was inserted and proper placement was confirmed by auscultation over the neck6. Maintenance of anesthesia was achieved with N2O 50\%, $\mathrm{O} 250 \%$ and propofolremifentanil infusion. He had spontaneous ventilation during surgery. Operation lasted for 90 minutes. There was not any untoward event during operation and recovery.

\section{Discussion}

Xeroderma pigmentosum is inherited as an autosomal recessive trait and the main characteristics of this disease include sunlight hypersensitivity, tremendous risk of skin cancer and neurologic disorders (1,3-5). First described by Kaposi in 1870, XP begins in childhood and progresses with premalignant and malignant lesions often leading to death in early adulthood.7 Classical types of XP have a defect in nucleotide excision repair (NER)3. Patients suffering from $X P$ present with many preoperative and intraoperative difficulties for anesthesiologists, like facial and oropharyngeal abnormalities leading to difficult intubation, prolongation of neuromuscular blockade, and the last but not the least; harmful effects of anesthetic drugs such as inhalation agents on nucleotide excision repair (1, 3-5). Volatile anesthetic agents should not be used in patients with XP because these drugs may exacerbate the symptoms of the disease. There are reports that volatile agents can impair NER in XP patient cells (3) Therefore, intravenous anesthesia is the recommended technique of general anesthesia in patients with XP. Furthermore, XP patients have an unusual sensitivity to neuromuscular blocking drugs because of the neuronal and muscular dysfunction. Therefore, minimal use of muscle relaxants is recommended; and wherever possible, regional anesthesia should be preferred over general anesthesia $(4,8)$.

We opted for intravenous general anesthesia using LMA due to possible genotoxic effects of volatile agents, unusual sensitivity to neuromuscular blocking drugs and the risk of difficult laryngoscopy and intubation. The airway manipulation was performed as little as possible and the surgical procedure was performed uneventfully.

\section{Conclusion}

TIVA anesthesia is a more appropriate alternative to inhalational anesthesia as a method for maintenance of general anesthesia for xeroderma pigmentosum patients. In these patients, airway manipulation must be performed as little and noninvasive as possible. 


\section{Ethical approval}

The written informed consent of the patient was taken for publication of this case report.

\section{Reference}

1. Soen M, Kagawa T, Uokawa R, Suzuki T. Anesthetic management of a patient with xeroderma pigmentosum. Masui. 2006; 55(2):215-7.

2. Hasanoglu A Gücüyener K, L Tümer et al. Association of xeroderma pigmentosum with thrombasthenia. Turk J Pediat, 1996; 38:261-264.

3. Masuda Y, Imaizumi H, Okanuma M, Narimatsu E, Asai Y, Namiki A. anesthesia for a patient with xeroderma pigmentosum. Masui. 2002; 51(2):169-71.

4. Miyazaki R, Nagata T, Kai T, Takahashi S. Anesthesia for a patient with xeroderma pigmentosum. Masui. 2007; 56(4):439-41.

5. Oliveira CR, Elias L, Barros AC, Conceição DB. Anesthesia in patient with xeroderma pigmentosum: case report. Rev Bras Anestesiol. 2003; 53(1):46-51.

6. Golzari SE, Mahmoodpoor A. Laryngeal mask airway in medical emergencies. N Engl J Med. 2014; 27;370(9):883. doi: 10.1056/NEJMc1315505\#SA2.

7. Orosco RK, Wang T, Byrne PJ. Xeroderma pigmentosum in an African-American. ORL J Otorhinolaryngol Relat Spec. 2011;73(3):162-5.

8. Shrestha GS, Sah RP, Amatya AG, Shrestha N. Anaesthetic management of patients with Xeroderma pigmentosum. A series of three cases. Nepal Med Coll J. 2011; 13(3): 231-2. 